\title{
Climate change and future populations at risk of malaria
}

Citation for published version (APA):

Martens, P., Kovats, R. S., Nijhof, S., de Vries, P., Livermore, M., Bradley, D. J., Cox, J., \& McMichael, A. J. (1999). Climate change and future populations at risk of malaria. Global Environmental Change, 9, S89S107. https://doi.org/10.1016/S0959-3780(99)00020-5

Document status and date:

Published: 01/01/1999

DOI:

10.1016/S0959-3780(99)00020-5

Document Version:

Publisher's PDF, also known as Version of record

Document license:

Taverne

Please check the document version of this publication:

- A submitted manuscript is the version of the article upon submission and before peer-review. There can be important differences between the submitted version and the official published version of record.

People interested in the research are advised to contact the author for the final version of the publication, or visit the DOI to the publisher's website.

- The final author version and the galley proof are versions of the publication after peer review.

- The final published version features the final layout of the paper including the volume, issue and page numbers.

Link to publication

\footnotetext{
General rights rights.

- You may freely distribute the URL identifying the publication in the public portal. please follow below link for the End User Agreement:

www.umlib.nl/taverne-license

Take down policy

If you believe that this document breaches copyright please contact us at:

repository@maastrichtuniversity.nl

providing details and we will investigate your claim.
}

Copyright and moral rights for the publications made accessible in the public portal are retained by the authors and/or other copyright owners and it is a condition of accessing publications that users recognise and abide by the legal requirements associated with these

- Users may download and print one copy of any publication from the public portal for the purpose of private study or research.

- You may not further distribute the material or use it for any profit-making activity or commercial gain

If the publication is distributed under the terms of Article $25 \mathrm{fa}$ of the Dutch Copyright Act, indicated by the "Taverne" license above, 


\title{
Climate change and future populations at risk of malaria
}

\author{
P. Martens ${ }^{\mathrm{a}, *}$, R.S. Kovats ${ }^{\mathrm{b}}$, S. Nijhof ${ }^{\mathrm{a}}$, P. de Vries ${ }^{\mathrm{a}}$, M.T.J. Livermore ${ }^{\mathrm{c}}$, D.J. Bradley ${ }^{\mathrm{d}}$, \\ J. Cox ${ }^{\mathrm{d}}$, A.J. McMichael ${ }^{\mathrm{b}}$ \\ anternational Centre for Integrative Studies, Maastricht University, PO Box 616, 6200 MD Maastricht, The Netherlands \\ ${ }^{\mathrm{b}}$ London School of Hygiene and Tropical Medicine, Department of Epidemiology and Population Health, Keppel Street, London, WC1E 7HT, UK \\ 'Jackson Environment Institute, School of Environmental Sciences, University of East Anglia, Norwich, NR4 7TJ, UK \\ ${ }^{\mathrm{d}}$ Department of Infectious and Tropical Diseases, London School of Hygiene and Tropical Medicine, Keppel Street, London, WC1E $7 H T$ UK
}

Received 2 June 1999

\begin{abstract}
Global estimates of the potential impact of climate change on malaria transmission were calculated based on future climate scenarios produced by the HadCM2 and the more recent HadCM3 global climate models developed by the UK Hadley Centre. This assessment uses an improved version of the MIASMA malaria model, which incorporates knowledge about the current distributions and characteristics of the main mosquito species of malaria.

The greatest proportional changes in potential transmission are forecast to occur in temperate zones, in areas where vectors are present but it is currently too cold for transmission. Within the current vector distribution limits, only a limited expansion of areas suitable for malaria transmission is forecast, such areas include: central Asia, North America and northern Europe. On a global level, the numbers of additional people at risk of malaria in 2080 due to climate change is estimated to be 300 and 150 million for $P$. falciparum and $P$. vivax types of malaria, respectively, under the HadCM3 climate change scenario. Under the HadCM2 ensemble projections, estimates of additional people at risk in 2080 range from 260 to 320 million for $P$. falciparum and from 100 to 200 million for $P$. vivax. Climate change will have an important impact on the length of the transmission season in many areas, and this has implications for the burden of disease. Possible decreases in rainfall indicate some areas that currently experience year-round transmission may experience only seasonal transmission in the future. Estimates of future populations at risk of malaria differ significantly between regions and between climate scenarios. (C) 1999 Elsevier Science Ltd. All rights reserved.
\end{abstract}

Keywords: Climate change; Malaria; Modelling

\section{Introduction}

The balance of scientific evidence suggests that human activities during the last century have begun to have a discernible influence on the world's climate, causing it to warm (IPCC, 1996a). Climate change is likely to have various impacts on human health. A major consequence of future changes in temperature and precipitation patterns would be changes in the incidence of diseases that are transmitted by insects, ticks or rodent species (McMichael et al., 1996; IPCC, 1996b). Climate plays an important role in the geographical distribution and seasonal abundance of these vector species. The anticipated

\footnotetext{
*Corresponding Author. Tel: + 31-43-3883555; fax: + 31-433884916.

E-mail address: p.martens@icis.unimaas.nl (P. Martens)
}

changes in temperature, precipitation, humidity and wind patterns will directly affect vector species reproduction, development and longevity. The distribution of vector-borne diseases in the human population is also limited by temperature in many regions where the climate is too cold for the parasite to complete its development in the insect host and be transmitted to people.

\subsection{Malaria: a global burden of disease}

Malaria is the world's most important vector-borne disease. About 2400 million people are at risk of contracting the disease and malaria is currently endemic in 92 countries, with pockets of transmission occurring in a further eight countries (WHO, 1997). There are $300-500$ million cases of malaria and more than $80 \%$ of these occur in sub-Saharan Africa. Worldwide, malaria accounts for more than one million deaths per year and 
the majority of these are in children under the age of five. Of all infectious diseases, malaria continues to be one of the biggest contributors to the global disease burden in terms of death and suffering.

Malaria was once effectively controlled in many parts of the world. Historically, socio-economic developments have reduced malaria transmission in many developed countries. In addition, specific control programmes such as spraying of insecticides were implemented in the 1960s and 1970s. These campaigns were successful in eradicating or controlling malaria in many areas in Asia and Latin America, and eradication from Europe. However, there was a limit to how long eradication efforts could be maintained, funds became limited, and areas of Africa had too high levels of transmission for effective control. The development of widespread resistance to insecticides and the drugs used to treat the disease have also contributed to the current global situation. Malaria is now prevalent in many countries where it had previously been controlled. In some countries, the incidence of malaria is even higher than it was before that era.

This assessment addresses the potential additional burden imposed by global climate change on the current world malaria situation. This has been done by linking transient climate change scenarios with an improved model of the relationship between climate variables and the transmission characteristics of malaria. Global estimates of the potential for malaria transmission were made based on simulations produced by the HadCM2 and the more recent HadCM3 global climate models developed by the UK Hadley Centre. The study represents one component of a "Fast Track" assessment of the impacts of climate change across several sectors at the global scale (Parry et al., 1999), based on climate change experiments conducted by the Hadley Centre.

\section{Study methods: modelling malaria}

\subsection{MIASMA}

The assessment of the impact of climate change on potential malaria transmission has been made using the MIASMA model developed in the Netherlands (e.g. Martens, 1998,1999; Martens et al., 1995a,b; 1997). MIASMA (Modelling framework for the health Impact ASsessment of Man-induced Atmospheric changes) is an acronym devised to refer to several models that address the health impacts of global atmospheric changes: climate change and vector-borne disease (dengue, malaria, schistosomiasis); climate change and thermal stress; stratospheric ozone depletion and skin cancer (Martens, 1998). The impact models are driven by scenarios of climate change, stratospheric ozone depletion, and population growth. The malaria model within MIASMA forms the base of the projections regarding future changes in populations at malaria risk due to climate change.

The malaria model used here has been improved in three main respects relative to the models used in previous assessments. The main developments are: (i) the inclusion of continental-scale estimates regarding the distribution of 18 main malaria vectors; (ii) the inclusion of species-specific relationships between temperature and transmission dynamics; (iii) a more realistic approach regarding malaria endemicity to explore changes in populations at various degrees of malaria risk (e.g. risk of epidemics vs. year-round transmission).

It is difficult to validate the model at the global scale because there is great uncertainty regarding the "natural" limits of malaria distribution (Molineaux, 1988). This is due in part to the lack of historical records describing the presence of malaria, and also because, at the fringes, malaria transmission is highly unstable; that is, only infrequent transmission occurs.

However, the malaria model has been validated at the country and regional level. This was done for the earlier version of the model that did not take into account regional differences in mosquito characteristics. For the African continent, and more specifically for Zimbabwe, the model was able to simulate both seasonal pattern of transmission and the distribution of transmission intensity by altitude within the country (Lindsay and Martens, 1998). The model was also validated using a time series of malaria cases in Colombia. The model output reproduced the interannual variation in malaria cases and the historical peaks, the latter in part related to El Niño (Poveda et al., 1999).

\subsubsection{Mosquito vectors and their distribution}

Malaria is transmitted by mosquitoes of the genus Anopheles. There are 422 known species distributed around the world but only about 70 species are vectors of malaria under natural conditions (Service, 1993). These species vary considerably in their ability to transmit malaria. The main vector species in Africa, the Anopheles gambiae complex, are the most efficient vectors in the world and are a major factor in the high burden of disease in this region.

Although Anopheles mosquitoes occur most frequently in tropical or subtropical regions they are also found in temperate climates. A large region in the Pacific Ocean (Polynesia and Micronesia) is currently free from Anopheles, and, therefore, malaria (Molineaux, 1988). Although malaria has been successfully eradicated from Western Europe and North America in the 1950s and 1960s, the vectors are still present (Bruce-Chwatt and de Zulueta, 1980).

It is difficult to obtain accurate and up-to-date estimates of species distributions. Vector surveys are unevenly distributed both within and between countries, and 
efforts to pool available data on presence/absence of specific malaria vector species have shown large areas where no reliable data exist (MARA, 1998). Field surveys of particular species are expensive, labour intensive and require laboratory support for the identification of species. Further, the success of eradication and control programmes in the 1950 s and 1960 s meant that the collection of this information was no longer seen as a priority. Now, many countries are unable to afford survey or control activities.

Fig. 1 illustrates the geographical distributions of the major mosquito species that have been incorporated into the model. The distributions in this assessment were derived from WHO (1989) and updated for Europe (Jetten and Takken, 1994). The 18 mosquito species were considered to be those with the most current or historical public health importance. Mosquitoes will probably change their distribution limits as climate changes. However, the introduction of mosquitoes into new habitats often occurs in an unpredictable manner and in most cases other factors than climate play an important role. Local geographical barriers and interaction/competition between species are important factors which determine whether species colonise the full extent of suitable habitat. Although there have been assessments of changes in vector distribution limits with climatic changes (e.g. Sutherst, 1998), future changes in mosquito species distribution under climate change were not estimated in this assessment.

Malaria is caused by species of parasites which belong to the genus Plasmodium. There are four species of the malaria parasite:

1. Plasmodium vivax has the most extensive geographic range and is present in many temperate zones as well as the tropics and subtropics;

2. P. falciparum is the most common species in tropical areas and the most dangerous clinically;

3. P. ovale resembles vivax and replaces it in West Africa.

4. P. malariae is much less apparent, with low parasitaemia, and found mainly in tropical Africa.

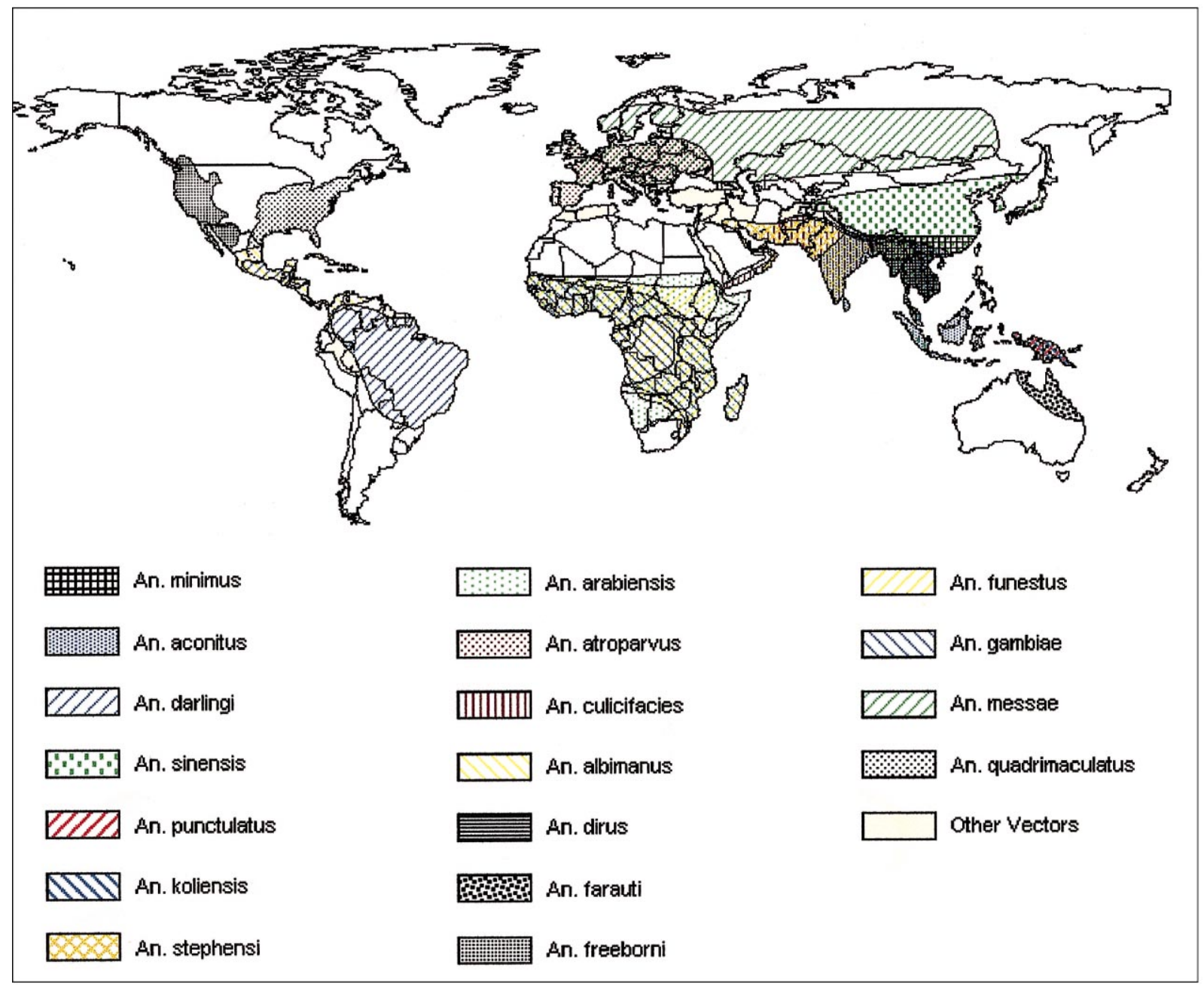

Fig. 1. Distribution of the most important mosquito vector species (WHO, 1989; Jetten and Takken. 1994). 
There is an important difference between parasites in the minimum temperature for parasite development, as well as differences in current health impact and distribution. Therefore, the assessment of the impact of climate change on transmission is presented separately for $P$. vivax and $P$. falciparum. $P$. ovale and $P$. malariae are not included in this assessment because of the small number of cases and limited distribution.

\subsubsection{Climate and malaria transmission potential}

The dynamics of the malaria vector populations are rapid compared to human population dynamics. Thus, vector dynamics can be assumed to be in equilibrium with respect to changes in the human population. A unit of measurement which encapsulates many of the important processes in the transmission of infectious diseases is the basic reproduction number $\left(R_{0}\right)$. In the case of the malaria protozoon, $R_{0}$ could be more precisely defined as the average number of secondary infections produced when a single infected individual is introduced into a potential host population in which each member is susceptible. $R_{0}$ is closely related to the vectorial capacity (VC), a unit of measurement often used in malaria epidemiology: $R_{0}$ is the $\mathrm{VC}$ multiplied by the duration of the infectious period in $R_{0}$ is the $\mathrm{VC}$ multiplied by the duration of the infectious period in people and the human susceptibility. If $R_{0}>1$ the disease will proliferate indefinitely; if $R_{0}<1$ the disease will die out.

The formula for the basic reproduction rate and vectorial capacity allows calculation of the critical density threshold of vector populations necessary to maintain malaria transmission. This "transmission potential" (TP) of malaria is defined as the reciprocal of the vector density threshold. In previous assessments, TP was referred to as the epidemic potential (EP). However, this term (EP) did not correctly describe the epidemiology of malaria because higher malaria transmission intensity does not necessarily mean an increased risk of epidemics.

TP is a comparative index for estimating the impact of changes in ambient temperature and precipitation patterns on the risk of malaria. A high TP indicates that, despite a smaller vector population, or, alternatively, a less efficient vector population, a given degree of transmission may be maintained in a given area. The main components of the TP are listed in Table 1.

$\mathrm{TP}=\frac{b^{*} c^{*} a^{2 *} p^{n}}{-\ln (p)}$

There are several important limitations to this approach. A number of assumptions used for deriving the vectorial capacity, and hence its derivative the transmission potential, are approximations to the real-world situation. Two examples are the assumption of homogeneous mixing of vectors and the assumption that vectors die at a constant rate, independent of age. Dye $(1986,1990)$ points out that at best, an estimate of the VC (or TP) will be useful as a "comparative index changing proportionally with the true vectorial capacity from site to site, from vector to vector, and within and between transmission seasons".

The incubation period of the parasite in the malaria mosquito (the extrinsic incubation period) must have elapsed before the infected vector can transmit the parasite. The parasites develop in the vector only within a certain temperature range. The minimum temperature for parasite development lies between 14.5 and $15^{\circ} \mathrm{C}$ in the case of $P$. vivax and between 16 and $19^{\circ} \mathrm{C}$ for $P$. falciparum. The proportion of parasites surviving decreases rapidly at temperatures over $32-34^{\circ} \mathrm{C}$ (Horsfall, 1955; Macdonald, 1957; Detinova et al., 1962). The relation between ambient temperature and the extrinsic incubation period is very important for assessing the impact of climate change. It is calculated using a temperature sum as described by Macdonald (1957):

$n=\frac{D_{\mathrm{m}}}{T-T_{\min , \mathrm{m}}}$,

where $n$ is the incubation period of the parasite inside the vector (in days), $D_{\mathrm{m}}$ the number of degree days required for the development of the parasite $\left(=105\right.$ and $111^{\circ} \mathrm{C}$ days for $P$. vivax and $P$. falciparum, respectively (Detinova et al., 1962)), $T$ the actual average temperature

Table 1

Main components of the malaria Transmission Potential

\begin{tabular}{|c|c|c|c|}
\hline Variable & Explanation & $\begin{array}{l}\text { Dependent on } \\
\text { vector species }\end{array}$ & $\begin{array}{l}\text { Dependent on } \\
\text { temperature }\end{array}$ \\
\hline$a$ & Human-biting rate: mosquito bites per person per day & Yes & Yes \\
\hline$b$ & Human susceptibility: Efficiency with which an infective mosquito infects a human & Yes & No \\
\hline$c$ & $\begin{array}{l}\text { Mosquito susceptibility: Chance that an uninfected mosquito acquires infection from } \\
\text { biting an infectious person }\end{array}$ & Yes & No \\
\hline$p$ & Daily survival probability of the mosquito. & Yes & Yes \\
\hline$n$ & Incubation period for the parasite inside the mosquito. & No & Yes \\
\hline
\end{tabular}


(between $T_{\min , \mathrm{m}}$ and a maximum temperature of about $40^{\circ} \mathrm{C}$ ) and $T_{\text {min,m }}$ the minimum temperature required for parasite development $\left(14.5\right.$ and $16^{\circ} \mathrm{C}$ for $P$. vivax and $P$. falciparum, respectively).

The number of blood meals a mosquito takes from human beings ( $a$ (/day)) is the product of the frequency with which the vector takes a blood meal and the proportion of these blood meals that are taken from humans. The human blood index (HBI) is the estimated proportion of the blood meals taken by a mosquito population which are obtained from humans (Garret-Jones, 1964; Garrett-Jones et al., 1980) and provides an indication as to whether a mosquito species is anthropophilic in its feeding behaviour (a high HBI indicates a preference for biting people) or zoophilic (a low HBI: species feeds mainly on animals). The index may vary between species, between locations, and over time. Furthermore, the availability of alternative hosts and environmental conditions influence the index. The frequency of feeding depends mainly on the rapidity with which a blood meal is digested (Detinova et al., 1962; Service, 1980), which increases as temperature rises. For a mosquito population, the shortening of the feeding interval $(u)$ can be calculated by means of a temperature sum (Detinova et al., 1962):

$u=\frac{D}{T-T_{\min }}$,

where $D$ is the number of degree-days required for the completion of the development, $T_{\min }$ is the temperature threshold and $T$ is the actual average temperature (ranging between $T_{\min }$ and the maximum temperature of about $40^{\circ} \mathrm{C}$ ). This relationship applies to the duration of the development of a bloodmeal and the gonotrophic cycle. The values of $T_{\min }$ and $D$ are $9.9^{\circ} \mathrm{C}$ and $36.5^{\circ}$ days, $12.6^{\circ} \mathrm{C}$ and $29.7^{\circ}$ days, and $8.9^{\circ} \mathrm{C}$ and $43.4^{\circ}$ days, for $A n$. maculipennis, An. culcifacies and An. stephensi, respectively (Detinova et al., 1962; Mahmood and Reisen, 1981). For the other Anopheles in the model, the An. maculipennis data are used.

The female mosquito has to live long enough for the parasite to complete its development if transmission is to occur. Longevity of the mosquito vector depends mainly on the vector species, humidity, the availability of hosts, and temperature. In previous experiments, we used a fitted relationship between temperature and the daily survival probability, dropping sharply at $35^{\circ} \mathrm{C}$ (Martens et al., 1995a,b,1997). In the present analysis, following Lindsay and Birley (1996), we estimated the daily survival probability $(p)$ using the survival rate per gonotrophic cycle; daily survival rate is thus dependent on changes in the length of the gonotrophic cycle, or blood digestion rate (Eq. (3)) as a function of temperature:

$p=x^{(1 / u)}$, where $x$ is the survival probability during one gonotrophic cycle and $u$ is the length of the gonotrophic cycle.

The probability of successful transmission of parasites to a susceptible human (b) depends partly on immune processes in and genetic differences between humans. Furthermore, the ability of mosquitoes to transmit different species of parasites, as denoted by the parameter $c$, shows a wide variability (Nedelman, 1985; Molineaux, 1988). Because there is neither reliable species specific information available, nor information about the dependency of both $b$ and $c$ on meteorological conditions, these parameters are assumed not to be climate sensitive and have been set to 1 (Jetten et al., 1996).

In Table 2 species-specific inputs used in the current assessment are given. Some of the values of the HBI and survival probability used in the simulations are derived from laboratory experiments and overestimate the values found in the field. This, in combination with a value of 1 for $b$ and $c$, will overestimate the absolute values of the TP. On the other hand, high values of the survival probability will mean a lower change of transmission risk. This is a result of the formula of the TP and the relationship between temperature and $p$. The settings of these variables do not influence the calculation of the population at risk as discussed in the next sections.

The basic malaria model has undergone extensive sensitivity and uncertainty analyses (Martens, 1998). Varying the values of the parameters in the TP equation that are most sensitive to temperature, namely vector survival probability and development time of the parasite, does not strongly influence the pattern of change of the TP. Moreover, the actual transmission intensity also depends on vector abundance (not modelled in this assessment), so that within the optimum temperature range for vector breeding and reproduction $\left(20-30^{\circ} \mathrm{C}\right)$ and where, in addition, rainfall and humidity are optimum, our results probably underestimate the actual change in transmission potential of malaria vector populations.

Rainfall plays a crucial role in malaria epidemiology. Mosquitoes breed in standing water (usually freshwater pools or marshes) and, therefore, mosquito abundance is affected by rainfall events. Rainfall also affects relative humidity and hence the longevity of the adult mosquito. This modelling exercise takes a simple approach of ensuring that rainfall occurs concurrently with the window of suitable temperature. A minimum level of monthly rainfall of $80 \mathrm{~mm}$ for at least 4 consecutive months is assumed to be essential for seasonal malaria transmission. The value of $80 \mathrm{~mm}$ per month was derived by the MARA (1998) project for Africa as a prerequisite for endemic malaria. Refinement of this parameter is currently being investigated within the MARA project (MARA, 1998). 
Table 2

Mosquito specific model inputs.

\begin{tabular}{|c|c|c|c|c|c|c|}
\hline Anopheles & $\begin{array}{l}\text { Human } \\
\text { blood } \\
\text { index }^{\mathrm{a}}\end{array}$ & References & $\begin{array}{l}\text { Gonotrophic } \\
\text { cycle }^{\mathrm{a}} \text { (days) }\end{array}$ & References & $\begin{array}{l}\text { Survival } \\
\text { probability } \\
\text { during } \\
\text { gonotrophic } \\
\text { cycle }\end{array}$ & References \\
\hline aconitus & $0.005-0.61$ & Boyd (1949) & - & & $0.5^{\mathrm{c}}$ & \\
\hline albimanus & $0.016-0.34$ & $\begin{array}{l}\text { Garrett-Jones (1964)/ } \\
\text { Hill (1934) in } \\
\text { Boyd (1949) }\end{array}$ & 2.6 & Mekuria et al. (1991) & $0.78^{\mathrm{b}}$ & Weidhaas et al. (1974) \\
\hline atroparvus & $0.06-0.84$ & $\begin{array}{l}\text { Pittalunga et al. (1932) } \\
\text { in Boyd (1949)/ } \\
\text { Swellengrebel and } \\
\text { de Buck (1938) in } \\
\text { Boyd (1949) }\end{array}$ & 3 & & $0.61^{\mathrm{b}}$ & Horsfall (1955) \\
\hline arabiensis & $0.23-0.88$ & $\begin{array}{l}\text { Githeko et al. } \\
\text { (1994)/Adugna and } \\
\text { Petros (1996) }\end{array}$ & 2.7 & Charlwood et al. (1995) & $0.37-0.78$ & Ijumba et al. (1990) \\
\hline culicifacies & $0.016-0.389$ & $\begin{array}{l}\text { Afridi et al. (1939) } \\
\text { in: Boyd (1949)/ } \\
\text { Dewit et al. (1994) }\end{array}$ & 2.2 & $\begin{array}{l}\text { Slooff and Herath } \\
\text { (1980) in } \\
\text { de Zoysa et al. } \\
(1988)\end{array}$ & $0.87^{\mathrm{b}}$ & de Zoysa et al. (1988) \\
\hline darlingi & $0.4^{\mathrm{c}}$ & & - & & $0.57-0.59$ & $\begin{array}{l}\text { Charlwood and Alecrim } \\
\text { (1989) }\end{array}$ \\
\hline dirus & 0.9 & Dutta et al. (1996) & - & & $0.5^{\mathrm{c}}$ & \\
\hline farauti & $0.68-0.75$ & Afifi et al. (1980) & $2-3$ & Afifi et al. (1980) & $0.78^{\mathrm{b}}$ & Afifi et al. (1980) \\
\hline freeborni & $0.4^{\mathrm{c}}$ & & 4 & McHugh (1989) & $0.30^{\mathrm{b}}$ & McHugh (1989) \\
\hline funestus & 0.613 & $\begin{array}{l}\text { Symes (1931) in } \\
\text { Boyd (1949) }\end{array}$ & 3.3 & Beier (1996) & $0.73^{\mathrm{b}}$ & $\begin{array}{l}\text { Garrett-Jones and Grabb } \\
\text { (1964) }\end{array}$ \\
\hline gambiae & $0.53-0.97$ & $\begin{array}{l}\text { Lindsay et al. } \\
\text { (1991)/Githeko et al. } \\
\text { (1994) }\end{array}$ & 3.8 & Beier (1996) & 0.59 & Bockarie et al. (1995) \\
\hline koliensis & 0.75 & Afifi et al. (1980) & $2-3$ & Afifi et al. (1980) & $0.70^{\mathrm{b}}$ & Afifi et al. (1980) \\
\hline messae & $0.005-0.63$ & $\begin{array}{l}\text { Barber and Rice (1935) } \\
\text { in: Boyd (1949)/ } \\
\text { Swellengrebel and } \\
\text { de Buck (1938) } \\
\text { in Boyd (1949) }\end{array}$ & - & & $0.61^{\mathrm{b}}$ & Horsfall (1955) \\
\hline minimus & $0.4^{\mathrm{c}}$ & & - & & $0.73^{\mathrm{b}}$ & Khan and Talibi (1972) \\
\hline punctulatus & $0.78-0.97$ & Afifi et al. (1980) & $2-3$ & Afifi et al. (1980) & $0.75^{\mathrm{b}}$ & Afifi et al. (1980) \\
\hline quadrimaculatus & $0.021-0.179$ & $\begin{array}{l}\text { King and Bull } \\
\text { (1923) Boyd (1949) }\end{array}$ & 5 & Jensen et al. (1993) & $0.5^{\mathrm{c}}$ & \\
\hline sinensis & $0.17-0.95$ & $\begin{array}{l}\text { Garrett- } \\
\text { Jones (1964)/ } \\
\text { Toumanoff and } \\
\text { Hu (1935) in } \\
\text { Boyd (1949) }\end{array}$ & - & & $0.89^{\mathrm{b}}$ & Horsfall (1955) \\
\hline stephensi & $0.054-0.204$ & $\begin{array}{l}\text { Motabar et al.(1975) } \\
\text { in Zahar (1985) }\end{array}$ & 2 & $\begin{array}{l}\text { Reisen et al. (1976) } \\
\text { in Zahar (1985) }\end{array}$ & $0.75^{\mathrm{b}}$ & $\begin{array}{l}\text { Reisen and Aslamkhan } \\
\text { (1979) on Zahar (1985) }\end{array}$ \\
\hline
\end{tabular}

\footnotetext{
${ }^{a}$ Wherever a range is given, the highest value is used in the simulation.

${ }^{\text {b }}$ The survival probability (SP) per Gonotrophic cycle was calculated by (daily survival probability ^ Gon.cycle (see text)).

${ }^{\mathrm{c}}$ If no data were found, the HBI was set to 0.4 and the SP during gonotrophic cycle to 0.5 . - No data available.
}

\section{The set of model experiments}

\subsection{Climate change scenarios}

This study uses five climate change scenarios based on simulations produced by the HadCM2 and HadCM3 global climate models (GCMs) (Hulme et al., 1999). These are applied to an observed global baseline climatology (1961-1990) (New et al., 1999). In this assessment monthly mean temperatures along with precipitation data are used.

An ensemble of four greenhouse-gas-only HadCM2 simulations (HadCM2GGa1-4) is employed. Each one uses a slightly different set of initial conditions leading to 
four subtly different climate futures being produced. The range of difference between the ensemble members gives an estimate of the natural variability present within the forcing scenario.

A single HadCM3-based, and thus un-flux-corrected, simulation is also used in this study. This more recent climate change scenario once again assumes greenhouse-gas-only forcings. The HadCM3 model is an improved version of HadCM2, which among other enhancements includes the use of individual gas members and an enhanced horizontal resolution over the oceans. None of the scenarios assume changes in sulphate aerosol emissions. For more information on the HadCM2 and HadCM3 models see Hulme et al. (1999).

\subsection{Population growth}

Scenarios of future population growth are used in this study to calculate the number of people at risk of malaria. The scenarios have been derived from the global database developed by Li (1996). The database contains gridded (one degree by one degree) information on the worldwide distribution of the population for the year 1990, based upon FAO and Guinness national population data, and the Rand McNally World Atlas (1991). National level projections produced by World Bank (Bos et al., 1994) were extracted from the World Bank's timeseries access and retrieval system and linked to the distri- bution database at the grid cell level via a relational database. Future population distributions were estimated for three time slices, the 2020s, 2050s and 2080s. This assessment uses the World Bank mid-range estimate of population growth, which estimates the total global population in 2020, 2050 and 2080 to be $\sim 8.1,9.8$ and 10.7 billion, respectively. The estimates of change in population at malaria risk are presented by region, based on areas defined by the World Health Organization: Africa, the Americas (we divided this region in North, Central and South America), Europe, Eastern Mediterranean, South East Asia and Western Pacific. These regions are illustrated in Fig. 2.

\section{Results}

\subsection{Impact of climate scenarios on potential transmission of malaria}

The TP is used to estimate the effect on malaria transmission potential of a change in monthly mean temperature and precipitation patterns, estimated using the HadCM2 and HadCM3 climate change scenarios. Wherever two vector species overlap, the most efficient vector is presented in the maps (i.e. the vector with the highest TP). Fig. 3 depicts the regions where currently malaria is being transmitted, the current distribution limits of the

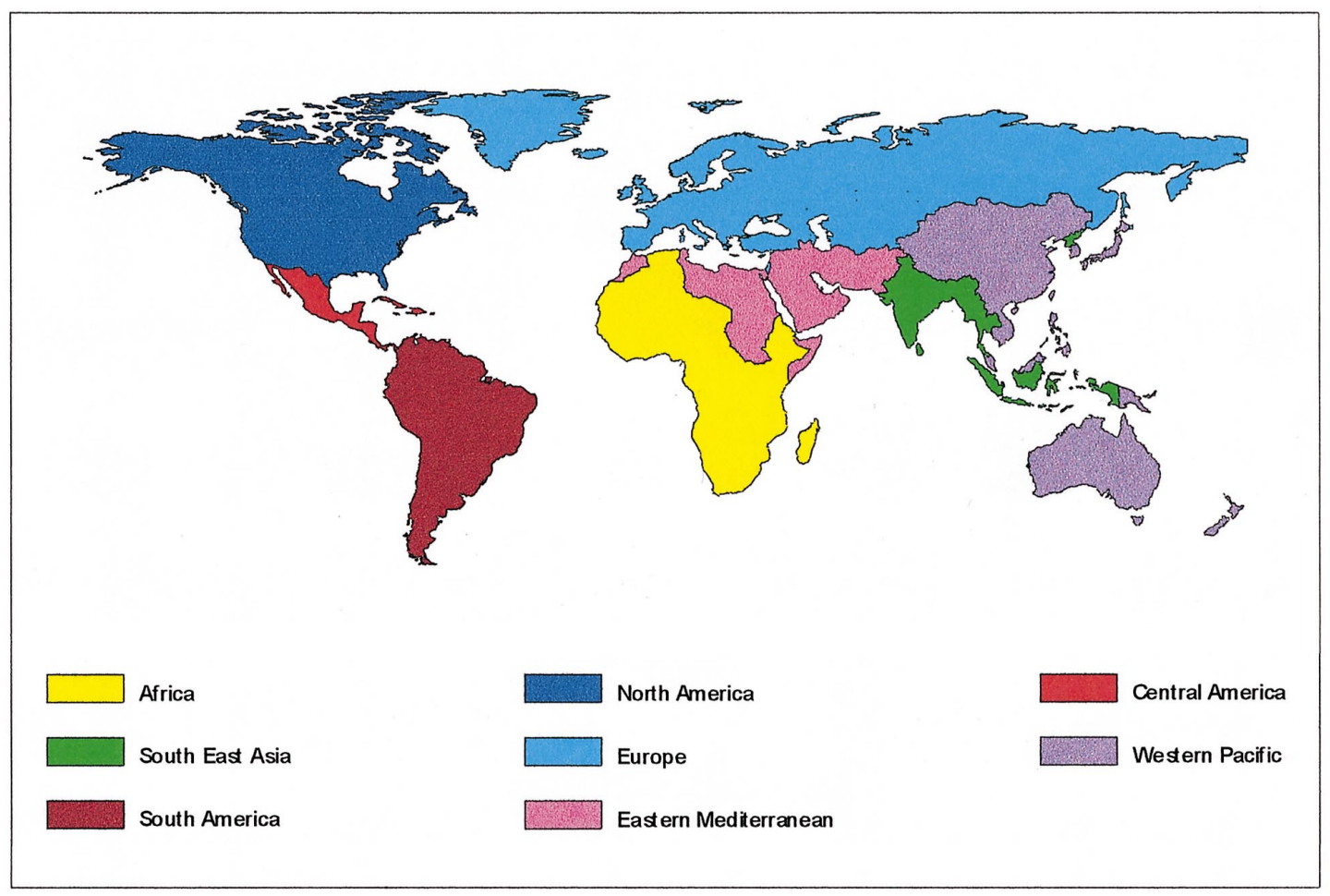

Fig. 2. The World Health Organization regions. 


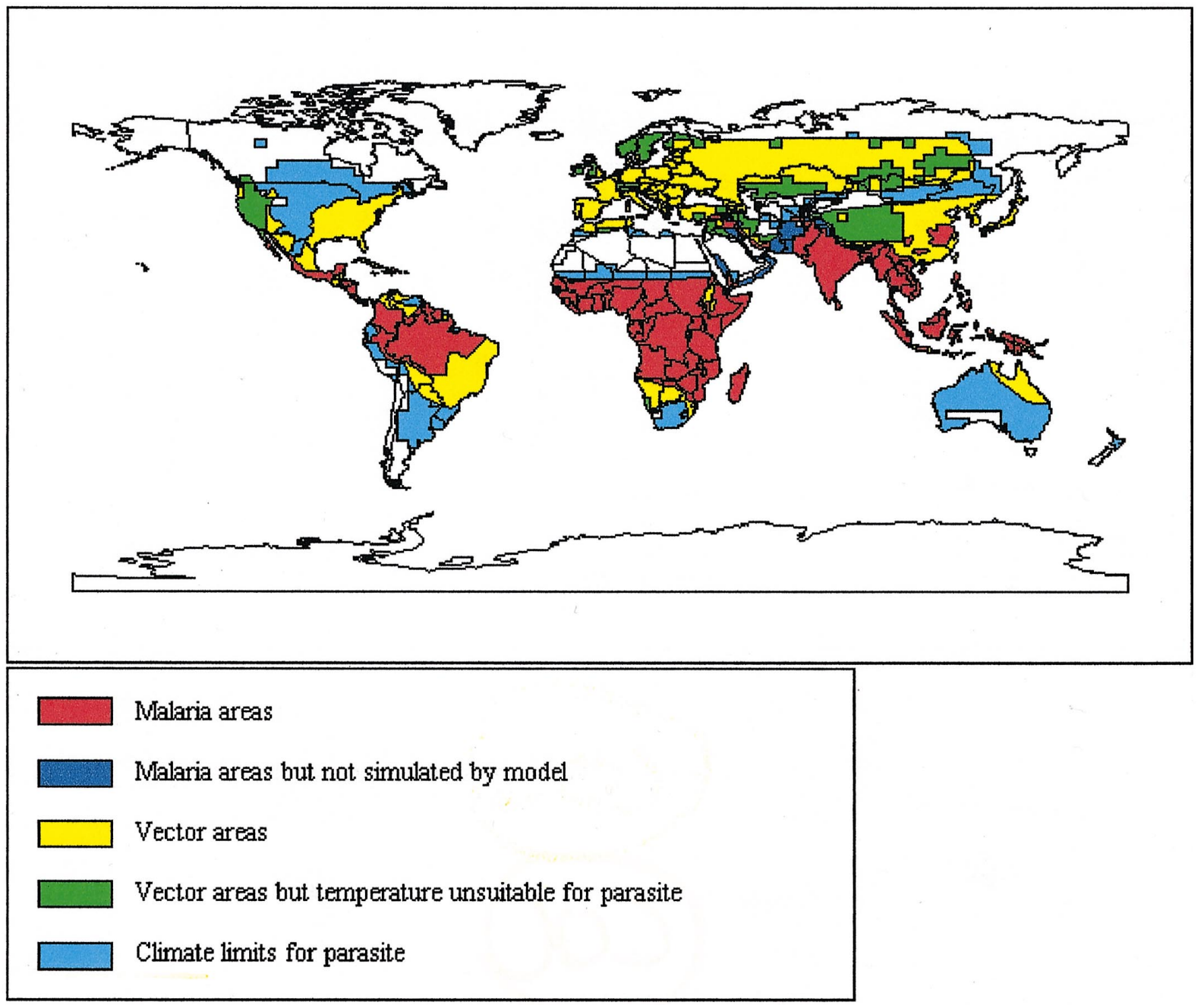

Fig. 3. Areas which are endemic for malaria in 1997 (WHO, 1997), the current vector distribution, and climate limits for development of $P$. falciparum for baseline-climate (1961-1990). (Note that the vector is present within the malaria areas, and that within the limits of the vector distribution, climate is suitable for parasite development (with the exception of the 'green' areas)).

malaria vectors, and the limits of the simulated potential geographical extent of malaria from observed climatology (1961-1990).

As can been seen from Fig. 3, there are only a few areas in the world where the vector is present but temperature prohibits parasite development (for example, An. sinensis is present in part of China where temperatures are not sufficient for either P. vivax and P. falciparum to develop). On the other hand, the model fails to simulate transmission in some areas of Eastern Mediterranean (e.g., Yemen and Oman). Here, malaria vectors (An. culcifacies) are present and temperature is suitable for transmission.
However, in this region our assumed precipitation limit of $80 \mathrm{~mm}$ per month is apparently too high. Of the potential transmission regions lying outside the vector distribution limits, only those bordering regions currently at risk in Africa, South America and South East Asia would be vulnerable. As they border the current malaria regions, the risk of introducing the parasite would be substantial (assuming the vector would expand its distribution (not modelled in this assessment)).

The changes in transmission potential for P. falciparum and $P$. vivax for the HadCM3 climate change scenario are presented in Fig. 4 for the 2020s, 2050s and 2080s. The

Fig. 4. Potential malaria transmission changes (P. falciparum) for the $2020 \mathrm{~s}, 2050$ s and 2080 s due to climate change, compared to the baseline (1961-1990), due to the HadCM3 climate change scenario (based on monthly mean temperature and precipitation). (b) Potential malaria transmission changes (P. vivax) for the 2020s, 2050s and 2080s due to climate change, compared to the baseline (1961-1990) due to the HadCM3 climate change scenario (based on monthly mean temperature and precipitation) 

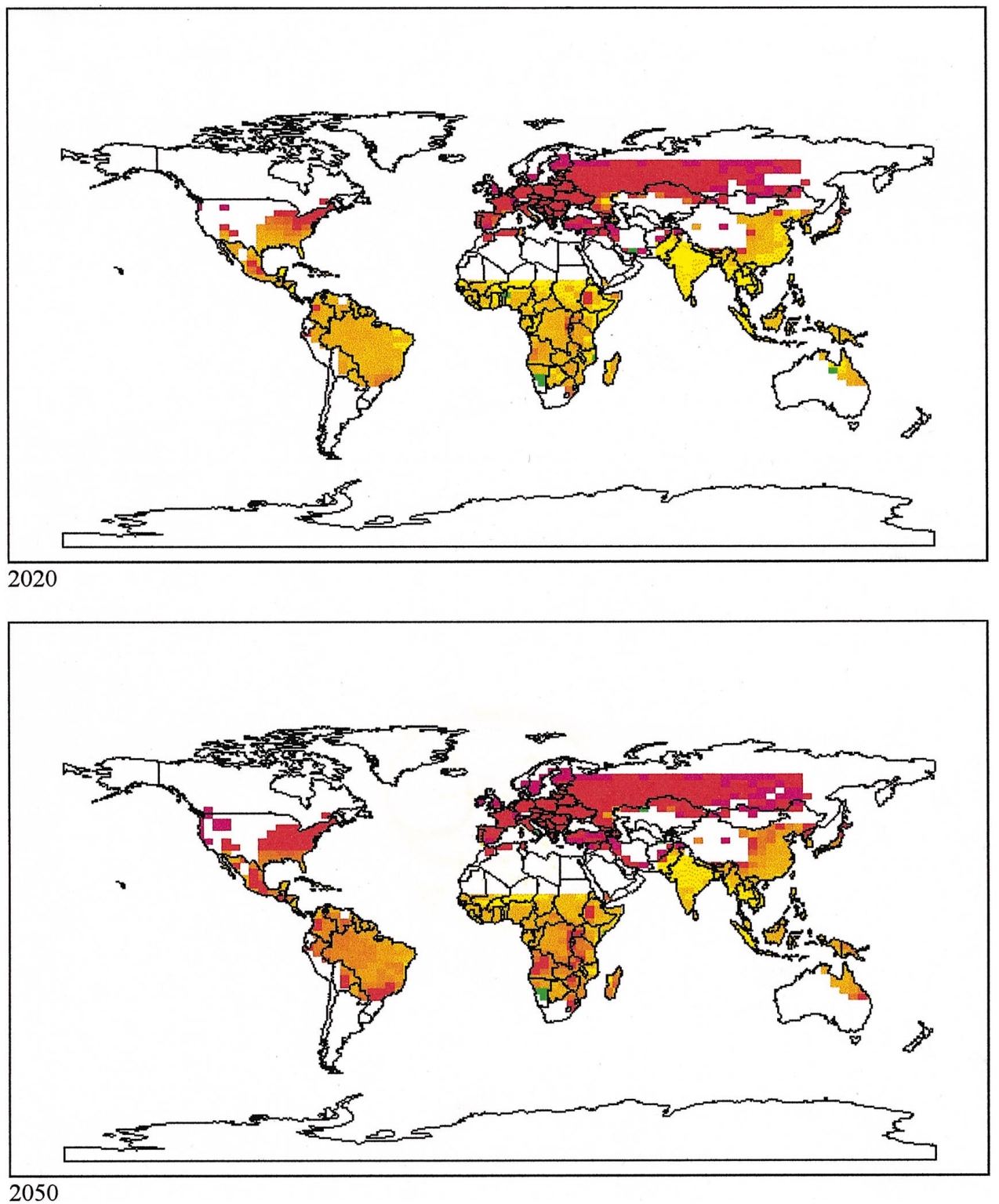

$>2$

- 1.9 to 2

1.8 to 1.9

- 1.7 to 1.8

1.6 to 1.7

-1.5 to 1.6

1.4 to 1.5

1.3 to 1.4

1.2 to 1.3

1.1 to 1.2

1 to 1.1

decrease

new risk

(a)
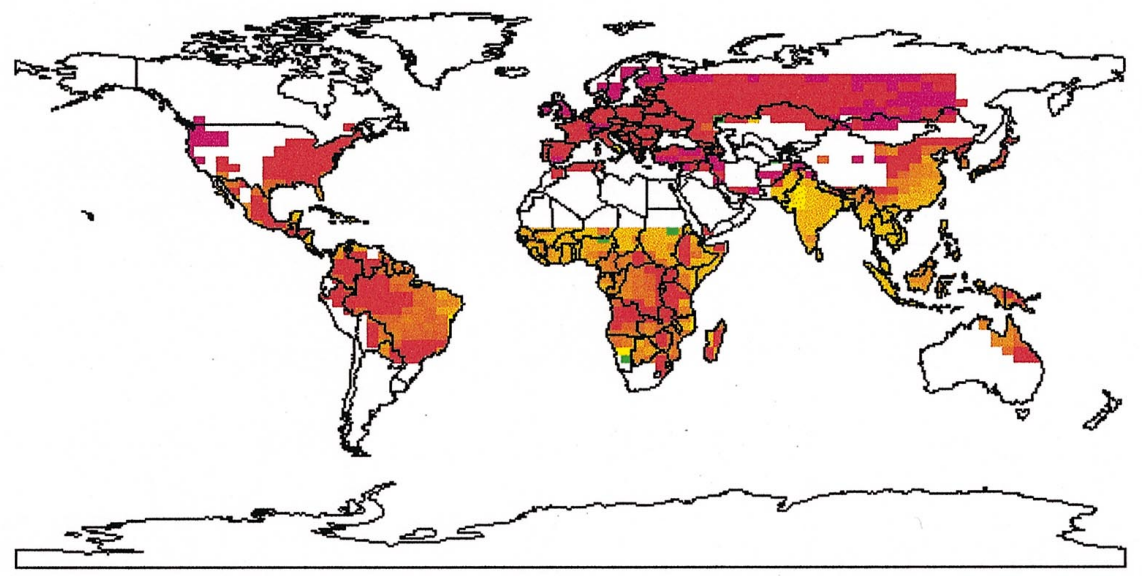

Fig. 4 (continued) 

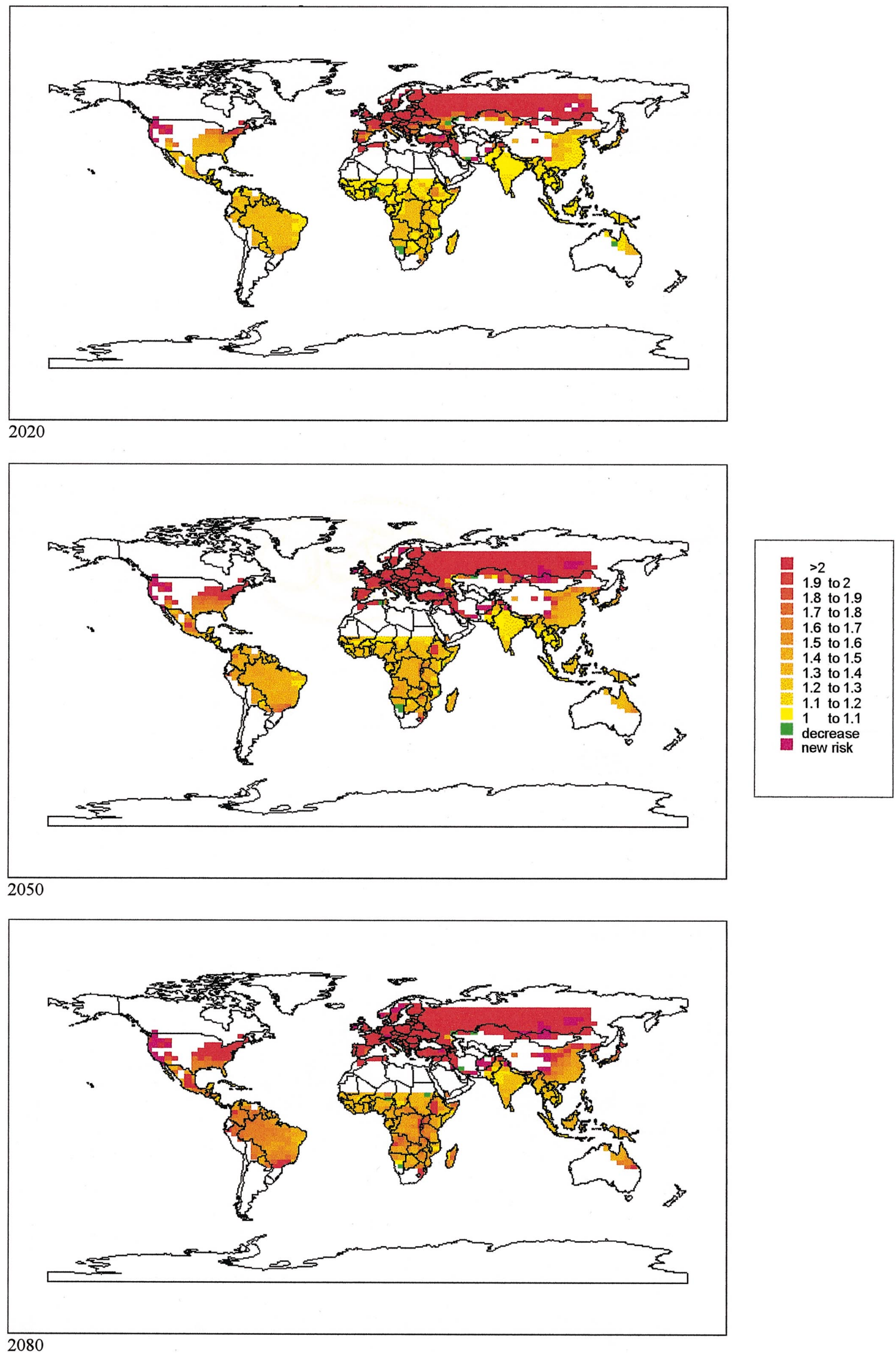

Fig. 4 (continued) 
climate change scenarios used in this assessment have a geographically variable change in precipitation - high latitude, equatorial and some sub-tropical regions have an increase, mid-latitude and some sub-tropical regions have a decrease (Hulme et al., 1999) - and a general increase in temperature. All regions of the world show an increase of malaria transmission potential as climate changes. A few 'green' areas indicate a decrease in TP (although this does not necessarily mean a decrease in risk (see next section)).

The magnitudes of the estimated changes in transmission potential depend on the climate scenario and specific characteristics of the malaria vector concerned. The main relative changes (compared to low baseline-values of the transmission potential) occur in temperate areas, like North America and Europe. This is mainly caused by the fact that an increase of, for example, $1^{\circ} \mathrm{C}$ around the minimum transmission temperature causes a larger increase of the transmission potential than the same increase at higher temperatures. In general, the change of the TP of less competent mosquito species (i.e. with initially low TP values) is higher than the change of the TP of species that have higher TP values at baseline climate.

Within the current distribution limits of malaria vectors, only a limited expansion of the geographical areas suitable for malaria transmission is to be expected as the climate warms (the purple regions in Fig. 4). There is a clear-cut projected change in risk in the middle of Asia (including parts of China), North America, and in North Europe. In these regions the vector is present but the development of the parasite has hitherto been inhibited by temperature. For all climate change scenarios, temperatures will become high enough for the parasite to develop (although this will be limited to a small number of months per year (see also Fig. 5)).

Comparison of potential distribution of malaria with the current observed distribution indicates that the simulation of future risk areas must take into account human activities that have eradicated or controlled the disease. Thus, countries in North America, Europe, and parts of China and South Africa, and Australia no longer experience epidemic or endemic transmission. However, sporadic local transmission does occur in these areas. This is because such areas still satisfy the conditions for local transmission, i.e. the presence of a competent mosquito vector in densities adequate to support transmission and suitable climatic conditions that allow completion of the sporogonic cycle in the mosquito (Holvoet et al., 1983). The increased number of people importing malaria infections from abroad may also play an important role in reintroducing the parasite in these regions.

Of particular importance is the increase of transmission potential at higher altitudes within malarial areas such as the eastern highlands of Africa or the Andes region in South America, where an increase in temper- ature of several degrees may raise the transmission potential sufficiently to change normally non-malarial areas into being subject to seasonal epidemics. Malaria in tropical Africa and other tropical countries differs much from that in the more temperate regions. In tropical climates the critical mosquito densities are several times lower than those required in cooler climates to maintain malaria at a positive endemic level.

\subsection{Changes in populations at risk}

In addition to the TP, that gives an indication of malaria risk in different areas, we also looked at the temporal distribution of the transmission potential over the course of the year as an additional determinant of the actual burden of malaria. The burden of malaria depends on whether transmission occurs year round or for only a few months a year. In stable malarious areas, the prevalence of infection is persistently high during the entire year or almost the entire year and only a little affected by natural or man-made change in the factors of transmission. In areas of lower endemicity, however, where the transmission is seasonal, the prevalence is very sensitive to even relatively small changes. Stability increases with the endemic level (Molineaux, 1988).

The world's population can be classified according to the seasonality and endemicity of the malarial situation in which they live. Based on the transmission potential, we classified malaria risk in three ways:

- Risk of epidemics (RE) - low values of TP for three or less than three consecutive months a year.

- Seasonal transmission (ST) - TP $>0$ for more than three, but less than seven consecutive months.

- Year-round transmission (YT) - TP $>0$ for seven or more consecutive months.

The 'population at risk' is defined as the total population living in an area where conditions are suitable for malaria transmission, meaning the presence of the vector, adequate precipitation and temperatures suitable for parasite development.

Several limitations surround this division into three classes. The classes are presented here in consecutive order. However, this does not necessarily reflect the burden of disease. Humans are capable of developing a partial immunity for malaria and maintaining this immunity when they are exposed to malaria infections regularly. Hence it is possible that in an area with year-round transmission fewer people at some ages are actually burdened by malaria than in an area with seasonal transmission. One should realise that not everyone of the population classified as at risk is actually at risk: socialeconomic circumstances allow some communities to take appropriate measures against malaria transmission. 
Baseline

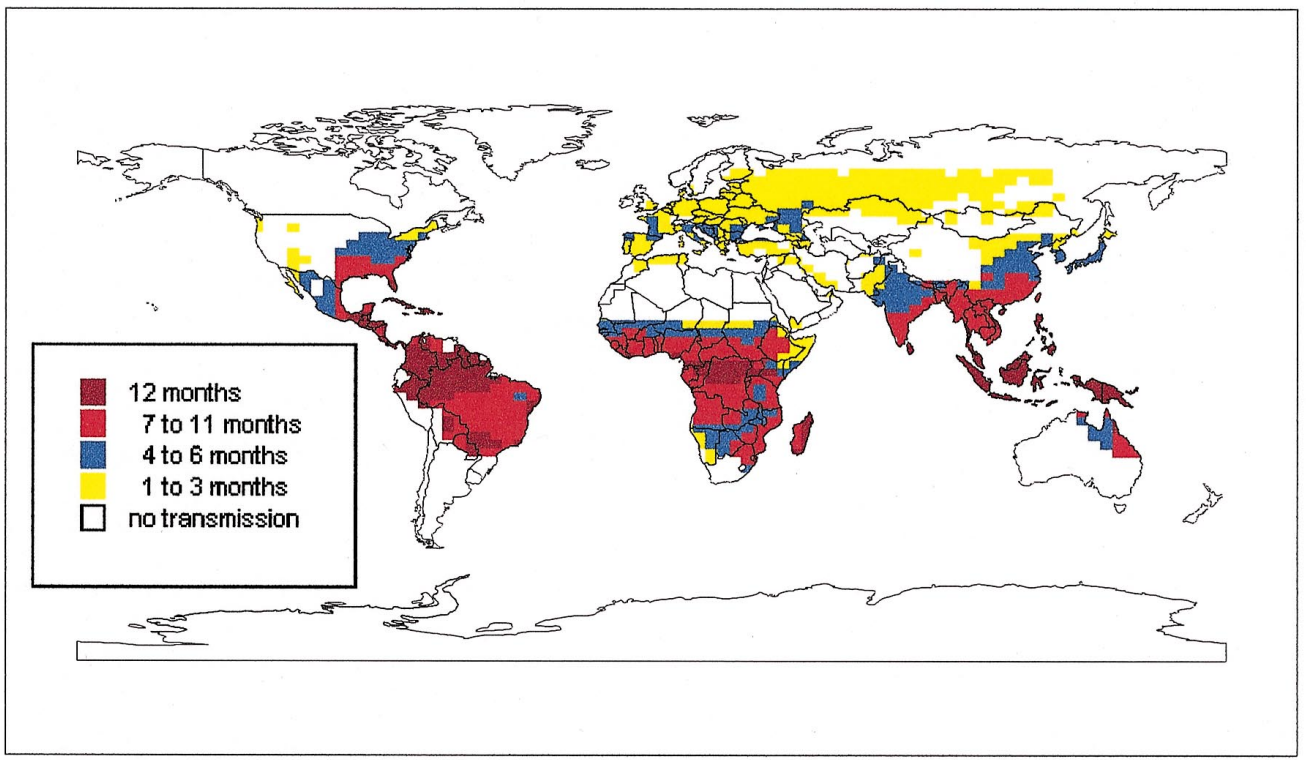

\section{HadCM2GGa1}

Fig. 5. Temporal pattern of malaria transmission within the population at risk for the baseline climate (1961-1990) and for the 2080s, due to five different climate change scenarios.

Furthermore, a substantial part of the people will live in cities where malaria risk may be different than in surrounding rural areas.

Another limitation of the division into these categories is that changes within each class remain undetected in the model outcomes, i.e. a change from 9 to 7 months transmission or from 1 to 3 months does not lead to a change of risk category. The disease burden might potentially increase, even if no change can be seen on the risk category maps. (However, Fig. 4, showing changes of the $\mathrm{TP}$, does indicate changes within a risk class). Finally, in temperate regions, the Transmission Potential is in general slightly above zero for the transmission months. The 'risk of epidemic' in these regions is therefore less than the 'risk of epidemics' in, for example, Africa - where the transmission potential is several magnitudes higher. Nevertheless, this categorisation roughly enables us to explore changes in the temporal pattern of malaria transmission within the population at risk.

In Fig. 5 the changes in malaria risk categories are given. The absolute latitudinal limits of the population at risk are set by the current distribution limits of the 
$\operatorname{HadCM} 2 \mathrm{GGa} 2$
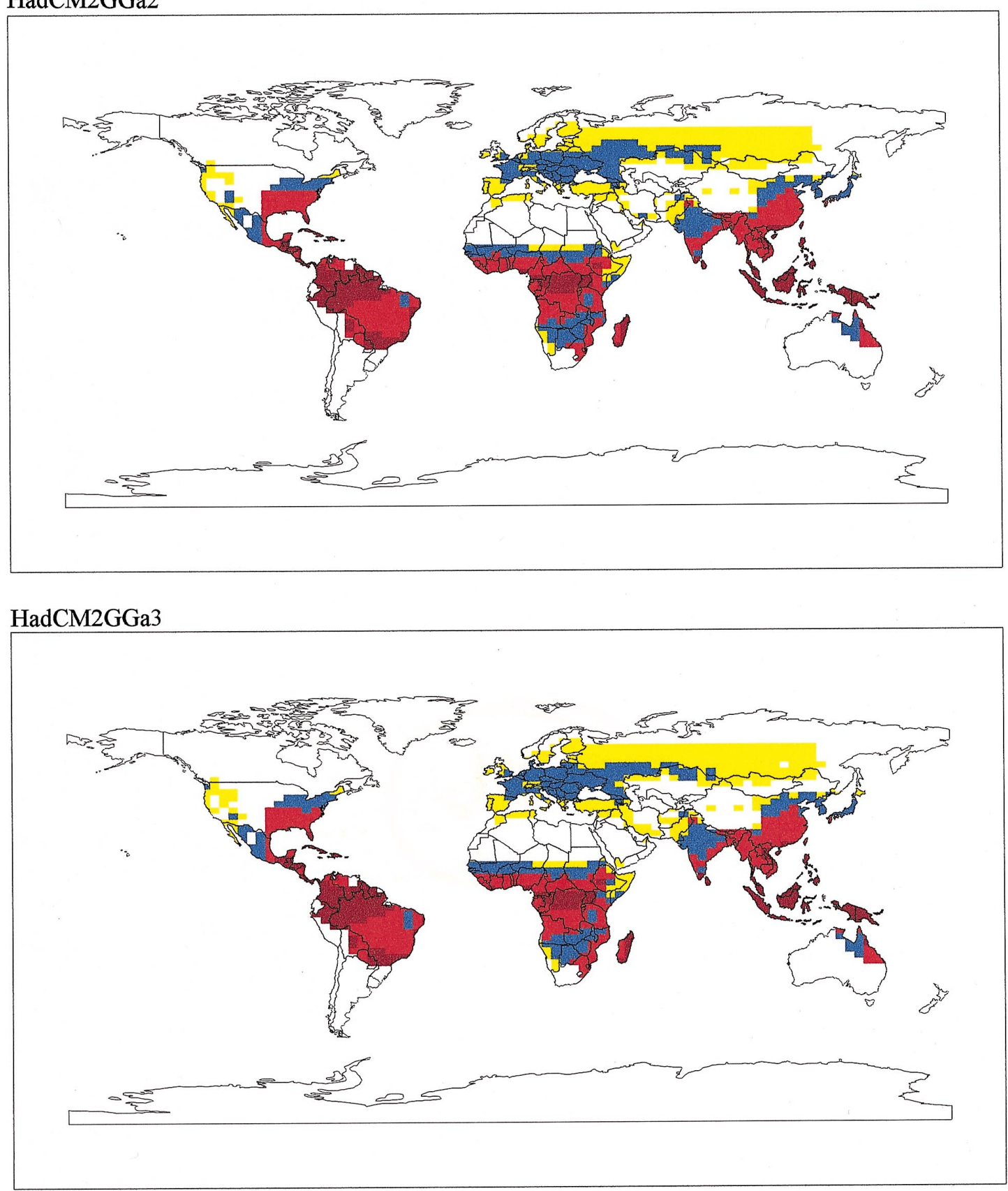

Fig. 5 (continued)

vector. As a consequence, total numbers of people at risk increase less than in previous published assessments where no vector distributions were included (e.g. Martens et al., 1997; Martin and Lefebvre, 1995).

High rates of population growth in malarious areas already entail an increase in population at risk. On a global level, the additional number of people at risk for $P$. falciparum is forecast to be $\sim 300$ million people in 2080 under the HadCM3 scenario. (Additional numbers are defined as the extra number of people at risk of malaria as a consequence of climate change. These are calculated by subtracting the base-line estimates (no climate change) from the populations at risk obtained according to the various scenarios.) The same figures for the HadCM2 ensemble runs may vary between an increase between approximately 260 and 320 million people. For $P$. vivax these numbers are an increase of 150 million people at risk for the HadCM3 scenarios, and an estimated increase between 100 and 200 million people for the HadCM2 runs towards 2080. 


\section{HadCM2GGa4}

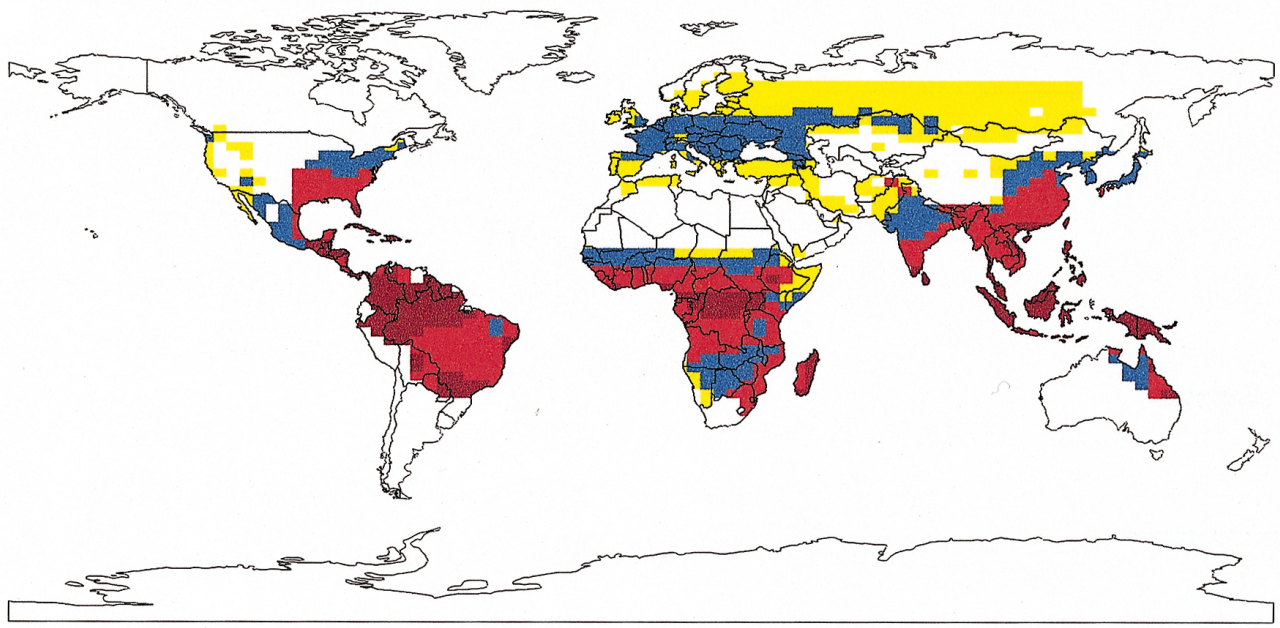

\section{HadCM3GGa1}

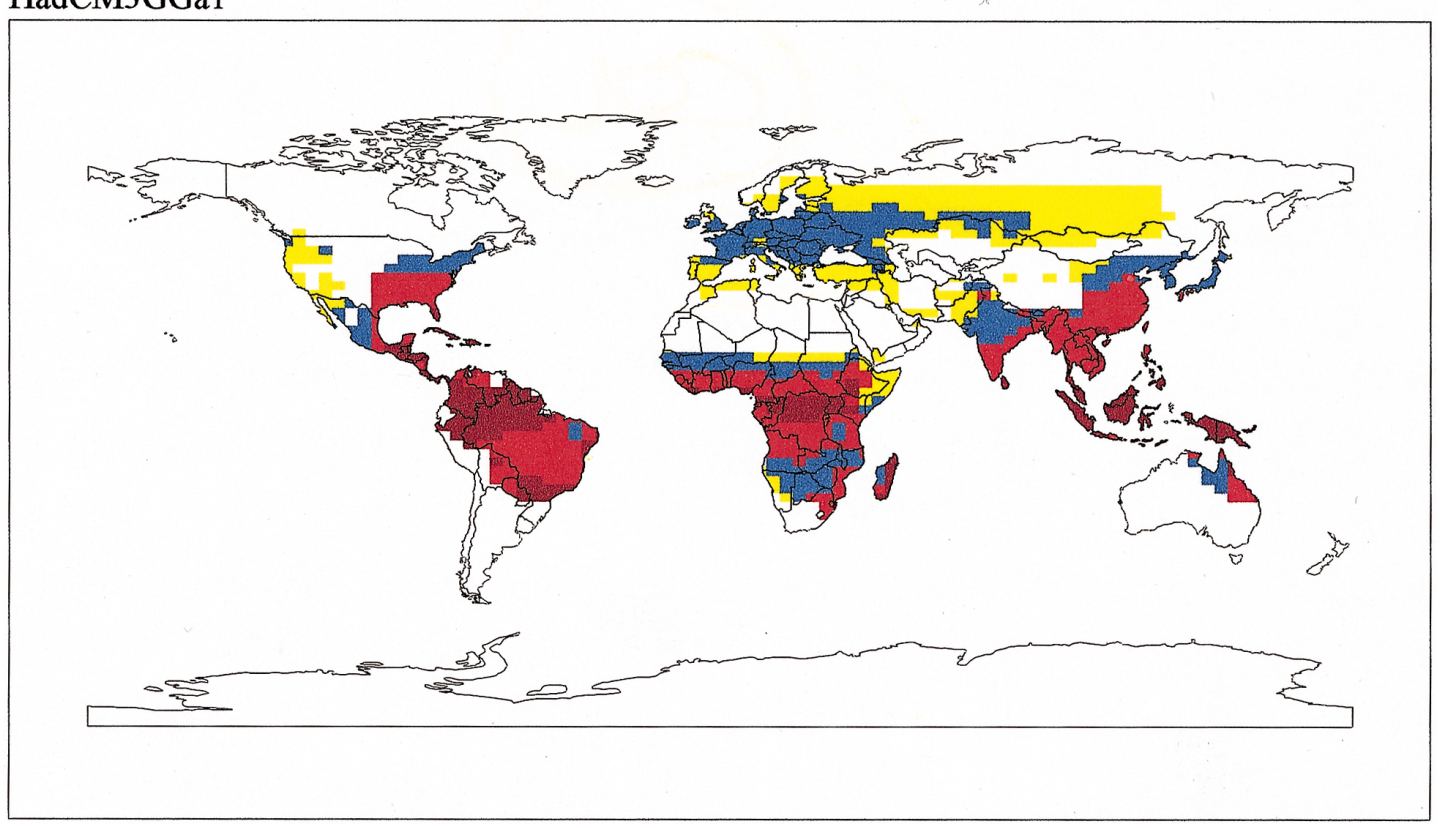

Fig. 5 (continued)

In Fig. 6 a comparison is made between model runs with the vector-distribution patterns as the limit of the expansion of malaria risk, and runs that consider climate limits only (i.e. conform to previous assessments). Obviously, the additional number of people at malaria risk is higher when the absence of the vector is not considered to be a limitation for transmission $(\sim 370$ million people for 'climate limits only' compared to $\sim 300$ million people in case vector-limits are taken into account) and previous assessments probably overestimated the people at risk of malaria. Furthermore, changes in populations at risk increase more for $P$. falciparum than for $P$. vivax, due to the lower development temperature of the latter. Figs. 7 and 8 shows the additional numbers of people at risk due to climate change on the global and regional level.

As appears from Figs. 5, 7 and 8, climate change may cause a change in the potential malaria transmission season. For both P. falciparum and P. vivax there is a profound change from one risk class to another, 


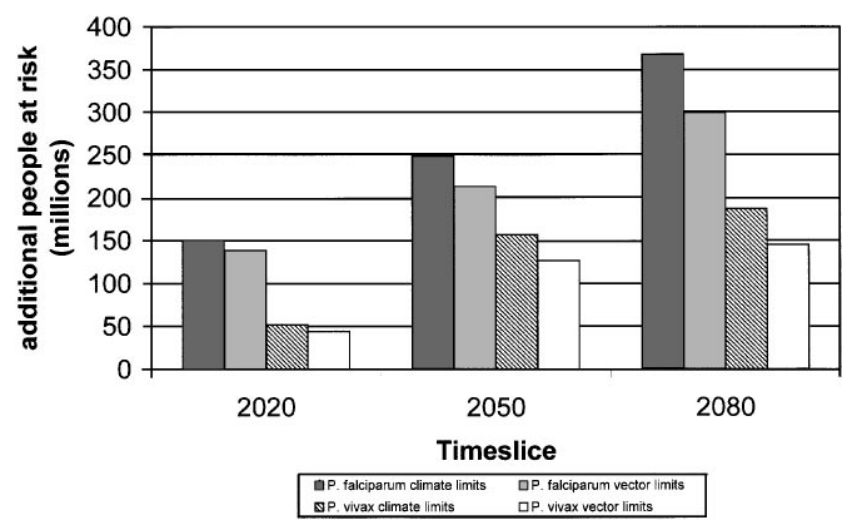

Fig. 6. World-wide additional numbers of people at risk of $P$. vivax and $P$. falciparum malaria (HadCM3 climate change scenario).

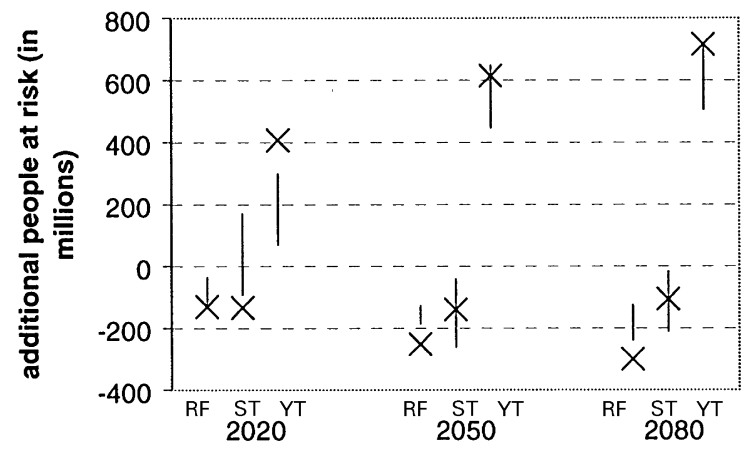

\section{P. falciparum}

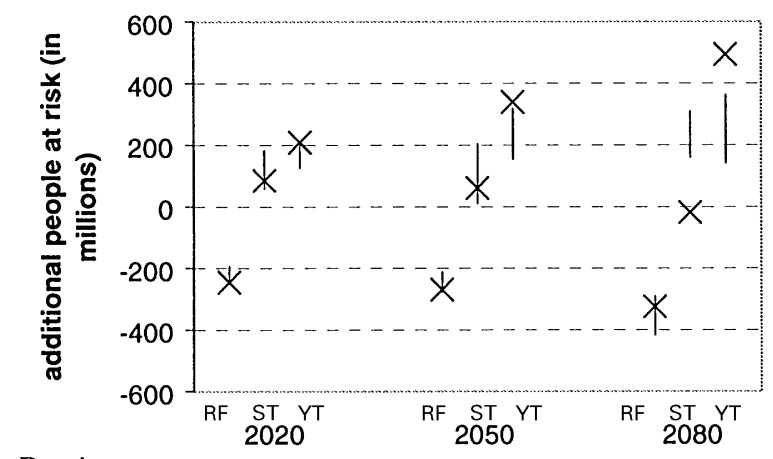

P. vivax

Fig. 7. Global climate change impacts on the additional numbers of people at risk of malaria. The ' $\mathrm{X}$ ' s show HadCM3-driven impacts while the HadCM2 range is depicted by the thin line. $\mathrm{RE}=$ risk of epidemics; $\mathrm{ST}=$ seasonal transmission; $\mathrm{YT}=$ year-round transmission.

significantly different between the HadCM scenarios. For most regions climatic changes according to the HadCM2 and HadCM3 runs entail more months suitable for malaria transmission. An area that is previously subject to risk of transmission for only a limited number of months might transform into one where transmission risk will be experienced for more than three months per year. Furthermore, in areas in which malaria was previously only transmitted during parts of the year, malaria may become year-round. A decrease in transmission months also occurs. As can been seen from Fig. 8, in Africa, the number of people in the second category (i.e. seasonal transmission) increases strongly. This is largely caused by some regions becoming too dry and consequently move from year-round transmission to 'seasonal transmission'. For example, the change in malaria risk in Southern Africa from 'seasonal transmission' to 'risk of epidemics' is caused by a decrease in precipitation, which decreases the number of months with enough rainfall for malaria.

Additional numbers of people at risk increases most in those regions where current climate is unsuitable for parasite development, but the vector is present. In the Eastern Mediterranean, for example, a climate change may transform large areas into potential risk areas of malaria. On the other hand, in, for example, Central America, malaria transmission areas are already at the limits of the vector distribution and consequently the increase in additional people at risk is small compared to other regions.

\section{Discussion}

Climate change is likely to affect malaria risk differently from region to region. The new results obtained by using all four internally consistent HadCM2 ensemble members and looking at the range of results obtained suggest that some regions will be subject to less stable climate conditions, with consequences for malaria transmission. The results show the major (regional) difference between the HadCM2 and HadCM3 scenarios. Also the changes in within-year temporal pattern vary considerably between the two scenarios.

It is anticipated that climate change will affect the seasonal transmission and geographical distribution of malaria. At the borders of malaria transmission, the modelled changes in average length of the transmission season may be important. This can be illustrated with a study in Pakistan (Bouma et al., 1994), where the prolongation of the transmission season by unusually high temperatures caused a substantially increase in the number of causes of falciparum malaria. On the other hand, the simulations also show that in most current high endemic regions an increase in seasonal transmission, at the expense of year-round transmission occurs. Although strongly varying between the climate change scenarios, this implies that the malaria situation in these regions moves towards unstable malaria.

There is strong evidence that malaria is a growing problem in the African highlands as there have been numerous reports of increased malaria in recent years 


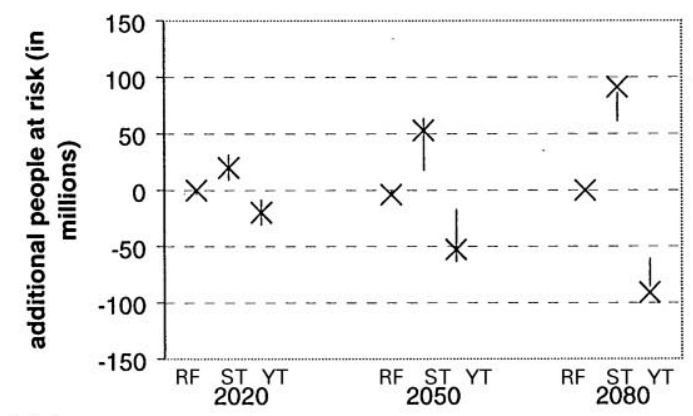

Africa

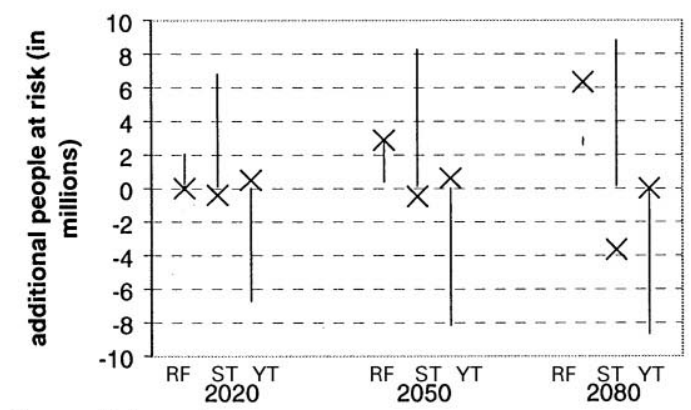

Central America

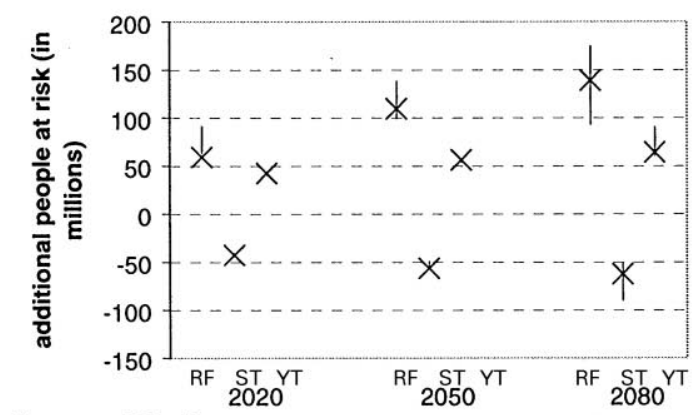

Eastern Mediterranean

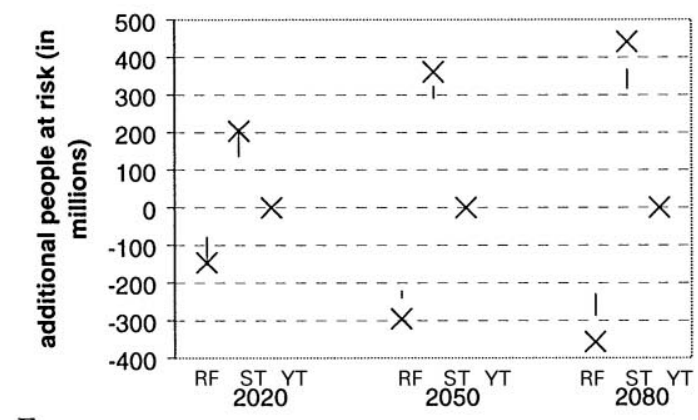

Europe

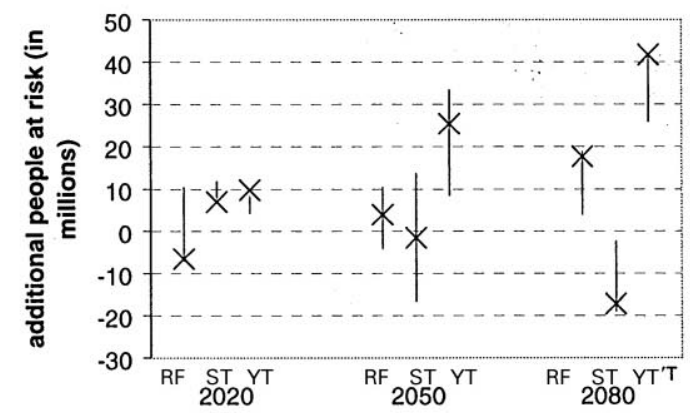

North America

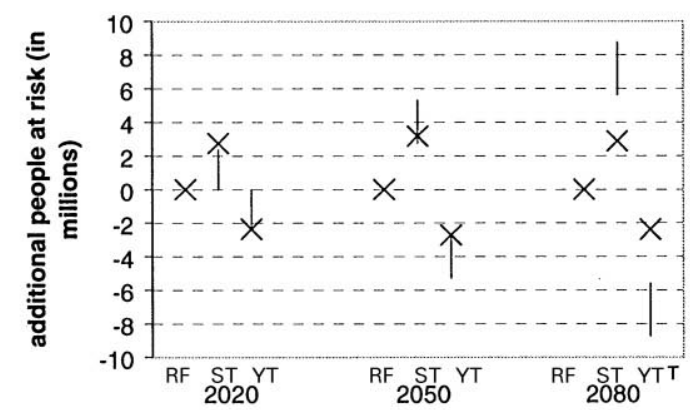

South America

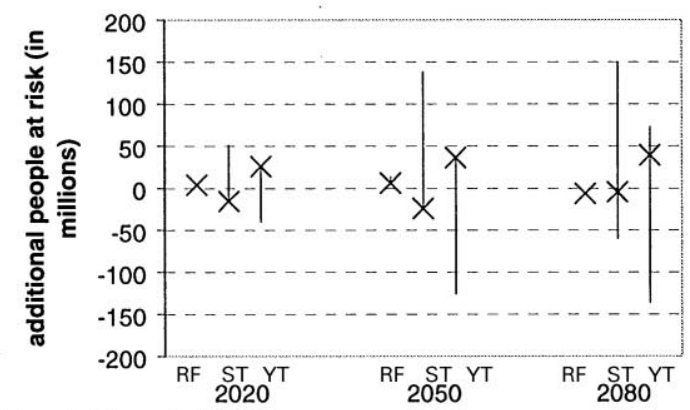

South East Asia

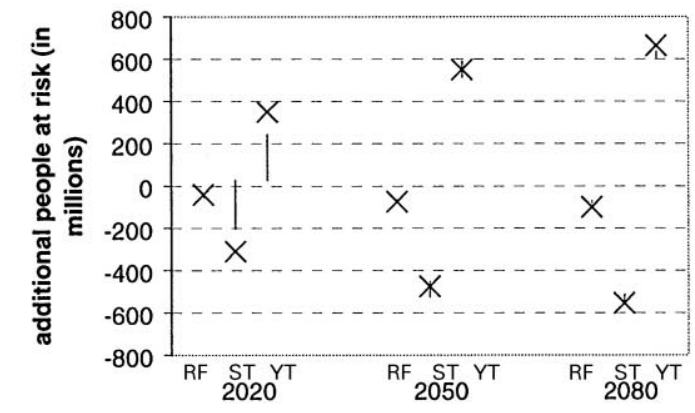

Western Pacific

Fig. 8. Regional climate change impacts on the additional numbers of people at risk of malaria (P. falciparum). The ' $\mathrm{X}$ ' s show HadCM3-driven impacts while the HadCM2 range is depicted by the thin line. RE = risk of epidemics; $\mathrm{ST}=$ seasonal transmission; YT $=$ Year-round transmission.

down the East African highland chain, from Ethiopia in the north to South Africa in the south (see e.g. Lindsay and Martens, 1998). However, it should be noted that the risk of increasing endemicity and more epidemics is dependent not just on climate factors, but also upon the vulnerability of highland communities and the capacity and capability of local health services. One of the major reasons for increasing malaria in recent years is probably due to a decline in the control and treatment of malaria. Whilst inadequate health care makes communities vulnerable to malaria, the factors which precipitate epidemics are often climatic in origin, including sharp 
increases in rainfall, temperature and humidity. It seems likely that epidemic prone areas are those which experience marked differences in interannual climate and where the thresholds required for malaria transmission are exceeded every few years.

Although malaria was successfully eradicated from Europe and North America in the 1950s and 1960s, the mosquito vectors are still present in these areas. Furthermore, between 1985 and 1989, it is estimated that 16,000 European travellers were infected with malaria (WHO, 1997). In the US, there are on average about $1000 \mathrm{im}$ ported cases reported each year (Zuker, 1996). Besides the introduction of the parasite, autochthonous malaria transmission in these regions would require the presence of a competent mosquito vector in densities adequate to support transmission and climatic conditions that allow completion of the sporogonic cycle in the mosquito. These conditions exist in Europe, Australia and the US during the summer months and autochthonous cases have been reported regularly (Holvoet et al., 1983; Baldari et al., 1998; Zuker, 1996). Climate change could increase this risk. Although is unlikely that an anthropogenic climate change would recreate a state of endemicity in most of these regions, three (Asian) countries in the WHO European Region (Azerbaijan, Tajikistan, and Turkey) are endemic (WHO, 1997). Although largely caused by a decline in public health infrastructure, this illustrates the vulnerability of these regions.

The results presented here are not predictions of the future. Rather, they show trajectories of possible changes in malaria risk, given the assumptions made. The authors are well aware of the many limitations of this model exercise. The malaria impacts are derived from only one GCM (albeit two versions of it) and from one 'forcing' future. Different GCMs and different forcings would yield different impacts (see also previous assessments, e.g. Martens et al., 1995a,b,1997). Species-specific information is included in the model, but the relationship between climate and transmission potential of malaria is still only partly understood, and many data on species behaviour are not available or are inaccurate. Furthermore, in addition to meteorological factors disease transmission dynamics are influenced by many other host, vector and ecosystem related factors, and the interactions among them. In endemic areas, habitat change due to climate and other factors such as irrigation may restrict or increase transmission due to alteration of breeding sites by new vegetation cover (Githeko et al., 1996).

Populations will respond (adapt) to changes in local malaria transmission associated with climate change. Adaptation responses will vary depending on the circumstances of the population at risk. It is difficult to develop assumptions about future adaptation to changes in disease risk associated with climate change. With planning and development of adaptation capacity, increases in disease incidence associated with climate change may be largely prevented. However, many of the current technical, socio-economic, and political barriers to successful prevention and control will also apply in the future. In most poor developing countries, the malaria burden of climate change will therefore be left unmitigated or be mitigated at high cost to the economy. In either case, the sustainability of human health and well being would be in greater jeopardy as without a human induced climate change.

\section{Acknowledgements}

The authors would like to express their gratitude to the Climate Impacts LINK Project (UK DETR Contract EPG 1/1/68) for its part in processing and distributing of the GCM results. This work was supported by the Department of Environment, Transport, and the Regions (UK DETR Contract EPG1/1/67), the Dutch National Research Program on Global Air Pollution and Climate Change (NOP) (Project Number 952257), and the Netherlands Foundation for the Advancement of Tropical Research (Project Number WAA 93-312/313). Comments on earlier versions of this paper from Petra Schneider, Bob Sturrock, Willem Takken, and the other members of the "Fast Track" group are gratefully appreciated.

\section{References}

Adugna, N., Petros, B., 1996. Determination of the human blood index of some anopheline mosquitos by using ELISA. Ethiopian Medical Journal 34 (1), 1-10.

Afifi, S.E., Spencer, M., Hudson, P.B., Tavil, N.W., 1980. Biting prevalence and malaria transmission patterns in the Anopheles punctulatus complex (Diptera: culicidae) in Papue New Guinea. Australian Journal of Experimental Biology and Medical Science 58 (1), 1-17.

Afridi, M.K., et al., 1939. Food preverences of anopheles mosquitos in the delhi urban area. Journal of the Malaria Institute of India 2, 219.

Baldari, M., Tamburro, A., Sabatinelli, G., Romi, R., Severini, C., Cuccagna, G., Fiorilli, G., Allegri, M.P., Buriani, C., Toti, M., 1998. Malaria in Maremma, Italy. The Lancet 351, 1246-1247.

Barber, M.A., Rice, J.B., 1935. Malaria studies in Greece: the malaria infection rate in nature and in the laboratory of certain species of anopheles of East Macedonia. Annals of Tropical Medicine 29, 329.

Beier, J.C., 1996. Frequent blood-feeding and restrictive sugar-feeding behavior enhance the malaria vector potential of Anopheles Gambiae s.l. and Anopheles funestus (Diptera: Culicidae) in western Kenya. Journal of Medical Entomology 33 (4), 613-618.

Bockarie, M.J., Service, M.W., Barnish, G., Toure, Y.T., 1995. Vectorial capacity and entomological inoculation rates of Anopheles gambiae in a high rainfall forested area of Sierra Leone. Tropical Medicine and Parasitology 46 (3), 164-171.

Bos, E., Vu, M.T., Massiah, E., Bulatao, R.A., 1994. World Population Projections 1994-95: Estimates and Projections with Related Demographic Statistics. World Bank. The Johns Hopkins University Press, New York.

Bouma, M.J., Sondorp, H.E., Kraay, van der, H.J., 1994. Climate change and periodic epidemic malaria. The Lancet i, 1440. 
Boyd, M.F., 1949. Epidemiology: Factors Related to the Definitive Host. In: Boyd, M.F. (Ed). Malariology, Vol. 1, W.B. Saunders Company, Philadelphia, pp. 608-697.

Bruce-Chwatt, L.J., Zulueta, J., de 1980. The Rise and Fall of Malaria in Europe: A Historico-Epidemiological Study. Oxford University Press, Oxford.

Charlwood, J.D., Alecrim, W.A., 1989. Capture-recapture studies with the South American malaria vector Anopheles darlingi, root. Annals of Tropical Medicine and Parasitology 83 (6), 569-576.

Charlwood, J.D., Kihonda, J., Sama, S., Billingsley, P.F., Hadji, H., Verhave, J.P., Lyimo, E., Luttikhuizen, P.C., Smith, T., 1995. The rise and fall of Anopheles arabiensis (Diptera Culicidae) in a Tanzanian village. Bulletin of Entomological Research 85, 37-44.

Detinova, T.S., Beklemishev, W.N., Bertram, D.S., 1962. Age-grouping Methods in Diptera of Medical Importance. WHO Monograph 47, World Health Organisation, Geneva.

Dewit, I., Coosemans, M., Srikrishnaraj, K., Wery, M., 1994. Population dynamics of anophelines in a malathion treated village in the intermediate zone of Sri Lanka. Annales de la Societe Belge de Medecine Tropicale 74(2), 93-104.

Dutta, P., Bhattacharyya, D.R., Khan, S.A., Sharma, C.K., Mahanta, J., 1996. Feeding Patterns of Anopheles dirus, the major vector of forest malaria in north east India. Southeast-Asian Journal of Tropical Medicine and Public Health 27(2), 378-381.

Dye, C.M., 1986. Vectorial capacity: must we measure all its components? Parasitology Today 2 (8), 203-209.

Dye, C.M., 1990. Epidemiological significance of vector-parasite interactions. Parasitology 101, 409-415.

Garrett-Jones, C., 1964. Prognosis for interruption of malaria transmission through assessment of the mosquito's vectorial capacity. Nature 204, 1173-1175.

Garrett-Jones, C., 1964. The human blood index of malaria vectors in relation to epidemiological assessment. Bulletin of the World Health Organization 30, 241-261.

Garrett-Jones, C., Grabb, B., 1964. The assessment of insecticidal impact on the malaria mosquito's vectorial capacity, from data on the proportion of parous females. Bulletin of the World Health Organization $31,71-86$

Garrett-Jones, C, Boreham, P.F.L., Pant, C.P., 1980. Feeding habits of anophelines (Diptera:Culicidae) in 1971-78, with reference to the human blood index: a review. Bulletin of Entomological Research. $70,165-185$.

Githeko, A.K., Service, M.W., Mbogo, C.M., Atieli, F.K., Juma, F.O., 1994. Origin of blood meals in indoor and outdoor resting malaria vectors in Western Kenya. Acta Tropica 58 (3-4), 307-316.

Githeko, A.K., Service, M.W., Mbogo, C.M., Atieli, F.K., 1996. Resting behavior, ecology and genetics of malaria vectors in largescale agricultural areas of Western Kenya. Parassitologia 38, 481-490.

Hill, R.B., 1934. Feeding habits of some Venezuelan anopheles. The American Journal of Tropical Medicine 14, 425.

Holvoet, G., Michielsen, P., Vandepitte, J., 1983. Autochtonous faciparum malaria in Belgium. Annales de la Societe Belge de Medecine Tropicale 63, 111-117.

Horsfall, W.R., 1955. Mosquitoes: their Bionomics and Relation to Disease. Hafner Publishing Company, New York.

Hulme, M., Mitchell, J., Ingram, W., Johns, T., New, M., Viner, D., 1999. Climate change scenarios for global impacts studies. Global Environmental Change, 9, S3-S19.

Ijumba, J.N., Mwangi, R.W., Beier, J.C., 1990. Malaria transmission potential of anopheles mosquitos in the Mwea-Tebere irrigation scheme. Kenya. Medical and Veterinary Entomology 4 (4), 425-432.

IPCC, 1996a. Climate change 1995: The Science of Climate Change. in Houghton, J.J., Meiro Filho, L.G., Callander, B.A., Harris, N., Kattenberg, A., Maskell, K. (Eds.), Cambridge University Press, New York.
IPCC, 1996b. Watson, R.T, Zinyowera, M.C., Moss, R.H, Dokken, D.J. (Eds.). Climate Change 1995: Impacts, Adaptations, and Mitigation of Climate Change: Scientific-Technical Analysis. Cambridge University Press, New York.

Jensen, T., Kaiser, P.E., Barnard, D.R., 1993. Short-term changes in the abundance and parity rate of anopheles quadrimaculatus species C (Diptera: Culicidae) in a central florida swamp. Jounal of Medical Entomology 30 (6), 1038-1042.

Jetten, T.H., Martens, P., Takken, W., 1996. Model simulations to estimate malaria risk under climate change. Journal of Medical Entomology 33 (3), 361-371.

Jetten, T.H., Takken, W., 1994. Anophelism with Malaria in Europe: a Review of the Ecology and Distribution of the Genus Anopheles in Europe. Wageningen Agricultural University Press, Wageningen.

Khan, A., Talibi, S., 1972. Epidemiological assessment of malaria transmission in an endemic area of East Pakistan and the significance of congenital immunity. Bulletin of the World Health Organization 46, 783-792.

King, W.V., Bull, C.G., 1923. The blood feeding habits of malariacarrying mosquitoes. The American Journal of Hygiene 3, 497.

Li, Y.F., 1996. Global population distribution database. A Report to the United Nations Environment Programme, under UNEP SubProject FP/1205-95-12, March 1996.

Lindsay, S.W., Birley, M.H., 1996. Climate change and malaria transmission. Annals of Tropical Medicine and Parasitology 90, 573-588.

Lindsay, S.W., Martens, P., 1998. Malaria in the African highlands: past, present and future. Bulletin of the World Health Organisation 76, 33-45.

Lindsay, S.W., Wilkins, H.A., Zieler, H.A., Daly, R.J., Petrarca, V., Byass, P., 1991. Ability of anopheles gambiae mosquitos to transmit malaria during the dry and wet seasons in an area of irrigated rice cultivation in The Gambia. Journal of Tropical Medicine and Hygiene 94, 313-324

Macdonald, G., 1957. The Epidemiology and Control of Malaria. Oxford University Press, London, U.K.

Mahmood, F., Reisen, W.K., 1981. Duration of the gonotrophic cycles of anopheles culcifacies giles and anopheles stephensi liston, with observations on reproductive activity and survivorship during winter in Punjab province. Pakistan. Mosquito News 41, 41-50.

MARA, 1998. Towards an atlas of malaria risk in Africa. First Technical Report of the MARA/ARMA Collaboration. MARA/ARMA, Durban

Martens, P., 1998. Health and Climate Change: Modelling the Impacts of Global Warming and Ozone Depletion. Earthscan Publications Ltd., London.

Martens, P., 1999. MIASMA: Modelling framework for the health impact assessment of man-induced atmospheric changes. ESIAM (Electronic Series on Integrated Assessment Modeling), CD-ROM no. 2.

Martens, P., Jetten, T.H., Focks, D.A., 1997. Sensitivity of malaria, schistosomiasis and dengue to global warming. Climatic Change 35, 145-156.

Martens, P., Jetten, T.H., Rotmans, J., Niessen, L.W., 1995a. Climate change and vector-borne diseases: a global modelling perspective. Global Environmental Change 5, 195-209.

Martens, P., Niessen, L.W., Rotmans, J., Jetten, T.H., McMichael, A.J., 1995b. Potential impact of global climate change on malaria risk. Environmental Health Perspectives 103, 458-464.

Martin, P.H., Lefebvre, M.G., 1995. Malaria and climate: sensitivity of malaria potential transmission to climate. Ambio 24 (4), 200-207.

McHugh, C.P., 1989. Ecology of a semi-isolated population of adult anopheles freeborni: abundance, trophic status, parity, survivorship, gonotrophic cycle length, and host selection. The American Journal of Tropical Medicine and Hygiene 41 (2), 169-176.

McMichael, A.J., Haines, A., Slooff, R., Kovats, S. (Ed.), 1996. Climate Change and Human Health. (WHO/EHG/96.7), World Health Organization, Geneva. 
Mekuria, Y., Granados, R., Tidwell, M.A., Williams, D.C., Wirtz, R.A., Roberts, D.R., 1991. Malaria transmission potential by anopheles mosquitos of Dajabon, Dominican Republic. Journal of the American Mosquito Control Association 7 (3), 456-461.

Molineaux, L (1988). The Epidemiology of Human Malaria as an Explanation of its Distribution, Including Some Implications for its Control. In: Wernsdorfer, W.H., McGregor, I. (Eds.) Malaria, Principles and Practice of Malariology vol. 2, Churchill Livingstone, New York, 913-998.

Motabar, M., Tabibzadeh, I., Manouchehri, A.V., 1975. Malaria and its Control in Iran. Tropical and Geographical Medicine 27, 71-78.

Nedelman, J., 1985. Introductory review: some new thoughts about some old malaria models. Mathematical Biosciences 73, 159-181.

New, M., Hulme, M., Jones, P.D., 1999. Representing twentieth century space-time climate variability. Part 1: Development of a 1961-1990 mean monthly terrestrial climatology. Journal of Climate 12, 829-956.

Parry, M., Arnell, N., Hulme, M., Friend, A., Martens, P., Nicholls, R., 1999. The global impact of climate change: a new assessment. Global Environmental Change, this issue.

Pittalunga, G., et al., 1932. Le Paludisme dans les "deltas". (Études sur certaines conditions naturelles et experimentales de l'anophelisme dans le delta de 'Ebre, 1926-1930) Archives Roumaines de pathologie expérimentale et de microbiologie 5, 5 .

Poveda, G., Graham, N.E., Epstein, P.R., Rojas, W., Quiñonez, M.L., Vélez, I.D., Martens, P., 1999. Climate and ENSO Variability Associated with Vector-Borne Diseases in Colombia. In: Diaz, H.F., Markgraf, V. (Eds.) El Niño and the Southern Oscillation, Multiscale Variability and Global and Regional Impacts. Cambridge University Press, Cambridge.

Rand McNally World Atlas, 1991. Rand McNally, New York.

Reisen, W.K., et al., 1976. Observations on the diel activity patterns of some Punjab Mosquitos (Diptera: Culicidae). Biologia (Lahore) 22, 67-77.

Reisen, W.K., Aslamkhan, M., 1979. Observations on the swarming and mating behavior of Anopheles culicifacies giles in nature. Bulletin of the World Health Organization 54 (2), 155-158.
Service, M.W., 1980. A Guide to Medical Entomology. Macmilan, London.

Service, M.W., 1993. The Anopheles Vector. In: Gilles, H.M., Warrell, D.A. Bruce-Chwatt's Essential Malariology. 3rd Edition, Arnold, London, pp. 97-123.

Slooff, R., Herath, P.R., 1980. Ovarian development and biting frequency in Anopheles culicifacies giles in Sri Lanka. Tropical and Geographical Medicine 32 (4), 306-311.

Sutherst, R.W., 1998. Implications of global change and climate variability for vector-borne diseases: generic approaches to impact assessments. International Journal of Parasitology 28, 935-945.

Swellengrebel, H.H., de Buck, A., 1938. Malaria in the Netherlands. Scheltema and Holkema, Ltd, Amsterdam.

Symes, C.B., 1931. Report on anophelines and malaria in the TransNzoia District. Kenya and East African Medical Journal (Nairobi) 8,64 .

Toumanoff, C., Hu, S.M.K., 1935. Sur le comportement trophique d'Anopheles hyrcranus var. sinensis dans le region de Shanghai. Bulletin de la Société de Pathologie Exotique 28, 832.

Weidhaas, D.E., Breeland, S.G., Lofgren, C.S., Dame, D.A., Kaiser, R., 1974. Release of Chemosterilized Males for the Control of Anopheles albimanus in El Salvador. The American Journal of Tropical Medicine and Hygiene 23(2), 298-308.

WHO, 1989. Geographical Distribution of Arthropod-borne Diseases and their Principal Vectors. WHO, Geneva.[WHO/VBC/89.967].

WHO, 1997. World malaria situation in 1994. Weekly Epidemiological Record 72, 269-276.

Zahar, A.R., 1985. Vector Bionomics in the Epidemiology and Control of Malaria. WHO publication.

Zoysa, A.P.K., de, Herath, P.R.J., Abhayawardana, T.A., Padmalal, U.K.G.K., Mendis, K.N., 1988. Modulation of Human Malaria Transmission by Anti-Gamete Blocking Immunity. Transactions of the Royal Society of Tropical Medicine and Hygiene 82, 548-553.

Zuker, J.R., 1996. Changing patterns of autochthonous malaria transmission in the United States: a review of recent outbreaks. Emerging Infectious Diseases 2, 37-43. 